\title{
Utilization of poly(methyl methacrylate) rejection blended with acrylonitrile butadiene styrene resins and the effect on product properties
}

\author{
Achmad Hanafi Setiawan ${ }^{1, *}$, Achmad Nandang Roziafanto ${ }^{2}$ \\ ${ }^{1}$ Polymer Chemistry Group, Pusat Penelitian Kimia-LIPI Kawasan PUSPIPTEK, Serpong 15314, Indonesia \\ ${ }^{2}$ Politeknik AKA Bogor, Jalan Pangeran Sogiri No.283 Tanah Baru Bogor 16121, Indonesia \\ *Corresponding author. Telp. +62217560929 , Fax: +62217560549 \\ E-mail: achmad.hanafi@gmail.com
}

Received: 9 May 2016 Revised: 4 October 2016 Accepted: 4 October 2016

\begin{abstract}
PMMA is one of the main raw materials for the injection molding process in the lens industries. Since this process requires extremely careful techniques to obtain lens with the best quality, it leads to a high rate of product rejection. These rejected products do not only pose an issue for the industrial environment and require storage space, their price also falls significantly. Among the solutions to this problem is to reuse the rejected products as substitute materials for the manufacture of another product's part such as lamp holders. This process reuses rejected PMMAcontaining products in the ABS base polymer industries so as to generate PMMA-containing products with better physical properties. In this experiment, 10 to $40 \%$ (w/w) of rejected PMMA was blended with ABS resins. The monomer content in the ABS resins was analyzed by NMR. Moreover, the mechanical, thermal, and morphological properties of the blended products were also examined. The NMR analysis showed that the resin contained 21.6 $\%$ butadiene monomer, in which its value was higher than the value required for materials with high-impact class application. The blend of resins and rejected PMMA $(10-30 \% \mathrm{w} / \mathrm{w})$ could increase the tensile strength value and decrease Izod impact strength and elongation percentage. The morphological analysis showed that this increased PMMA content may also result in widespread brittle areas. Since the blend was designed without compatibilizers, the DSC analysis indicated that the resulting blend in any ratios was not completely miscible. It was revealed that ABS resins containing 10\% PMMA was the best blend for the polymer engineering application and this blend still had adequate properties and elastomer content required.
\end{abstract}

Keywords: ABS, blending, properties, PMMA regrind.

\section{INTRODUCTION}

Poly(methyl methacrylate) (PMMA) is an important homopolymer in acrylic groups which has a high glass transition that can be used as raw materials for producing lens (Tsui et al., 2012; Sankar, et al., 2004). In motorcycle lamp manufacturing, the lamp structure consists of two parts, namely the lens and the lamp holder. The lamp holder surface will be applied with silver paste to be a reflector of the lamp. Based on the Indonesian National Standard No.7398:2008 concerning light reflectors for motor vehicles adapted from the UN-ECE (United Nations-Economic Commission for Europe) Vehicle Regulations No. 3 on uniform provisions concerning the approval of retro-reflecting devices for power-driven vehicles and their trailers, the raw materials for lamp holder (reflector) must have an adequate impact and heat resistance (SNI 7398, 2008).

PMMA is required for producing the lens section, while the lamp holder is made from acrylonitrile butadiene styrene (Kuo et al., 2016; Oepen \& Gottschalk, 2011). The injection molding process to prepare lens materials requires extremely careful techniques so that the resulting product is free from bubbles, weld-lines, scratches, silver streaks and cracks (Kenplas, 2016). This requirement leads to a high rate of rejected lens products, whereas the need of PMMA on these products is $50 \%$ of the total raw materials. These rejected products do not only pose an issue for the industrial environment and require storage space, their price also falls significantly.

Among the solutions to this problem is to reuse 
the rejected products as substitute materials for the manufacture of another product's part such as lamp holders. Since the rejected products consist of lens, their size needs to be reduced into smaller pieces using a grinder. Therefore, these materials are usually called the PMMA regrind. Although the concept of blending polymer has long existed, if the blended product reaches particular physical properties, it will be economically favourable (Alhydary et al., 2012). This blending process takes place physically in the form of contact surfaces so that there will be an interaction between the polymer molecules. The solubility parameter of polymers to be mixed and the polarity level of polymers are crucial factors in this process (Li et al., 2009). It is known that both ABS and PMMA are materials with polar areas and an adjacent melting point, thus allowing them to form a compact mix (Buthainadan \& Kadum, 2010; Alper et al., 2006). The mechanical and thermal properties of products with different weight ratios of both polymers shall be observed (Gaur et al., 2008; Polli et al., 2009).

\section{MATERIALS AND METHODS Materials}

The raw materials of the polymers used were ABS LG HI 121 produced by LG Chem. ( $\rho: 1.04 \mathrm{~g}$ / $\mathrm{cm}^{3}$; Tm: $220-25{ }^{\circ} \mathrm{C}$; MFR: $21.4 \mathrm{~g} / 10 \mathrm{~min}$ ), while the PMMA regrind was the by-product made from PMMA, i.e. $80 \mathrm{~N}$ Delpit Asahi Kasei ( $\rho: 1.19 \mathrm{~g} /$ $\mathrm{cm}^{3}$; r: 230-245 ${ }^{\circ}$; MFR: $\left.2.0 \mathrm{~g} / 10 \mathrm{~min}\right)$.

\section{Methods}

The process of blending ABS materials and the PMMA regrind was carried out using a twin screw extruder. There were different concentrations of PMMA regrind added to the ABS, namely $10 \%, 20 \%, 30 \%$, and $40 \%(\mathrm{~W} / \mathrm{W})$. The characterization equipment consisted of Rheomix Haake 3000; Hydraulic Hot Press 150 kg/cm Toyoseiki; Stereograph P-I Toyoseiki; Izod Impact Toyoseiki
40 kg.cm; SEM (Scanning Electron Microscopy) JEOL Scanning Microscope (JSM) 5310LV; and dog bone specimens which were prepared using the compression molding machine to comply with the standards of ASTM D638 and ASTM D256. The polymer structure prediction was identified using ${ }^{1} \mathrm{H}$ NMR supported by the software ChemDraw Ultra 10.

\section{RESULTS AND DISCUSSION \\ The Analysis of Monomer Composition in ABS Using NMR}

Fig. 1 presents the spectrum measurement result of ABS using NMR and Table 1 presents the content of each monomer in ABS calculated based on the peak area.

Table 1 shows that the ABS LG Chem. 121 contains styrene, butadiene, and acrylonitrile monomers with a ratio of $76 \%, 22 \%$, and $2 \%$, respectively. The percentage of each monomer in the ABS is specific for each polymer because the polymer manufacturer had it adjusted to the percentage of applications to be used. According to Oepen \& Gottschalk (2011), ABS with butadiene monomers at a percentage of greater than $18 \%$

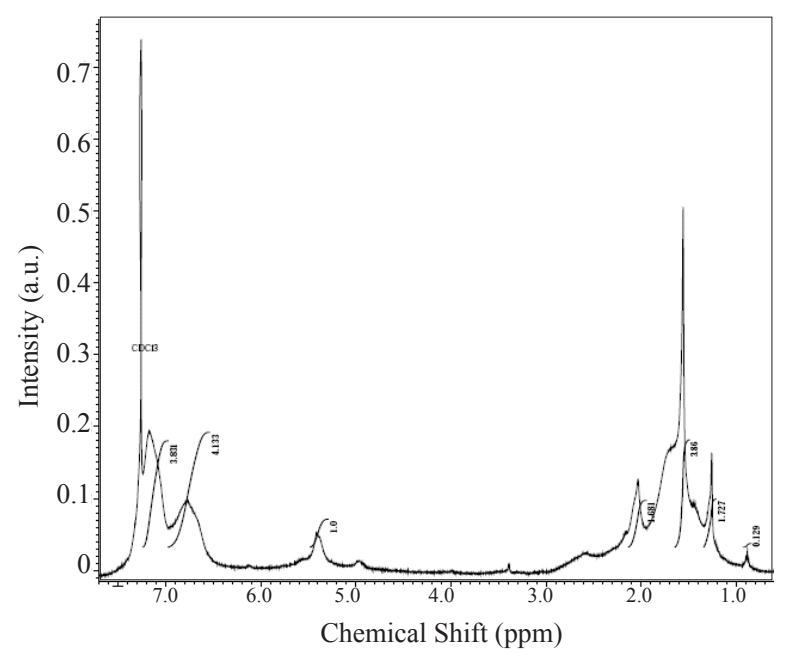

Fig 1. NMR spectrum output.

Table 1. Determination of the monomer content in ABS using the ${ }^{1} \mathrm{H}$ NMR instrument.

\begin{tabular}{lccc}
\hline Monomer & $\begin{array}{c}\text { ChemDraw Ultra Prediction } \\
(\mathrm{ppm})\end{array}$ & Peak Area & $\begin{array}{c}\text { Percentage } \\
(\%)\end{array}$ \\
\hline Acrylonitrile & 2.45 & 0.427 & 2.05 \\
Butadiene & $2.33-2.29$ & 2.211 & 21.61 \\
Styrene & 5.48 & 2.298 & 76.34 \\
\hline
\end{tabular}


belongs to engineering polymers with a high-impact class that is used for applications that require frequent impact and stress on the environment. Therefore, it can be calculated for the engineering polymer that the highest ratio between the PMMA and $\mathrm{ABS}$ resins is $(2: 9)$ or $18.2 \%$ PMMA in $\mathrm{ABS}$ resins.

Mechanical Properties of the ABS-PMMA Regrind Blend: The Effect of the PMMA Content

Fig. 2 describes the effect of the PMMA regrind content on the mechanical strength of the ABS-PMMA blend. The effect of the PMMA re-

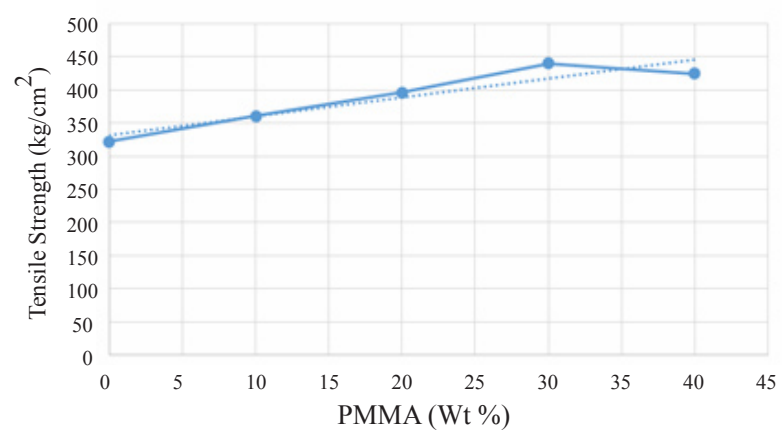

a)

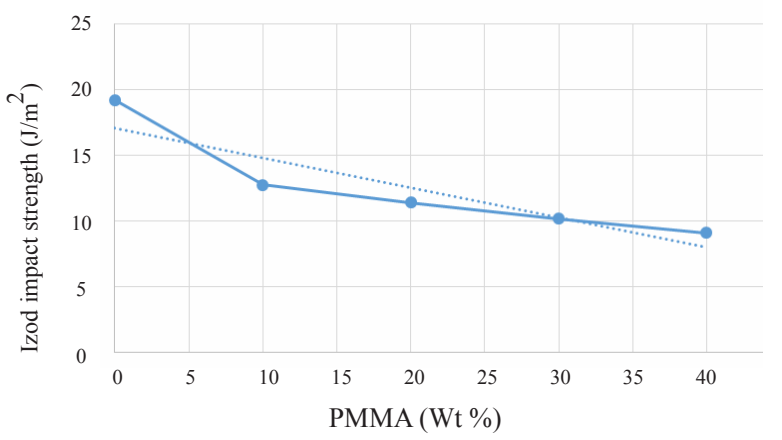

b)

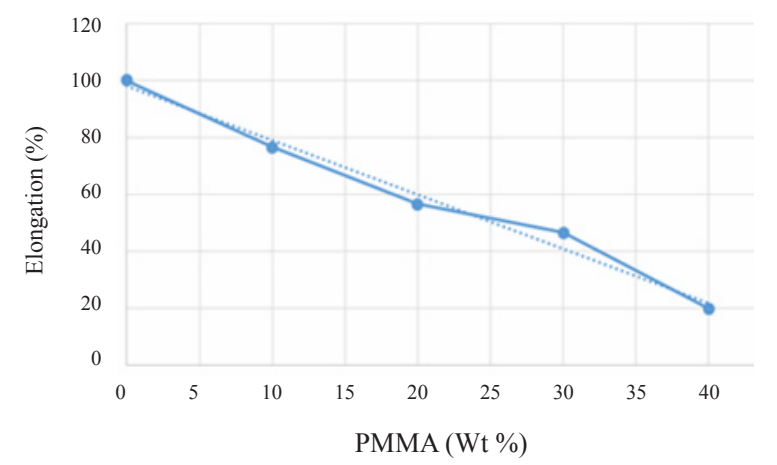

c)

Fig 2. The effect of the PMMA regrind content on the mechanical strength of the ABS PMMA blend a) Tensile strength; b) Izod impact strength, and c) Elongation. grind content on the tensile strength (Fig. 2A); the Izod impact strength (Fig. 2B); and the elongation percentage (Fig. 2C).

Fig. 2 shows that the increased PMMA regrind content will increase the tensile strength and decrease the Izod impact strength and the elongation percentage compared to those in ABS resins. Fig. 2a shows that the tensile strength of the ABS-PMMA blend increases almost linearly as the percentage of the PMMA regrind is increased. This indicates that the ABS-PMMA blend is harder than pure ABS polymers. At the 30\% PMMA content, the blended product obtains the strongest tensile strength, which is $37 \%$ stronger than the strength of ABS polymers without PMMA addition. From this graph, it can also be said that the addition of the $10 \%$ PMMA content $(\mathrm{w} / \mathrm{w})$ to the resins results in an increased strength by $7.7 \%$. Fig. $2 \mathrm{~b}$ shows the Izod impact strength of the ABS-PMMA blend decreases when the PMMA regrind content is increased. This indicates that the ABS-PMMA blend is less brittle than pure ABS polymers. At the $30 \%$ PMMA content, the Izod impact strength is $50 \%$ lower than that of pure ABS polymers, whereas, at the $10 \%$ PMMA content, it was decreasing to $35 \%$ lower than that of pure ABS polymers.

\section{Morphology of the Blended Product}

Fig. 3 shows the microstructure of the ABSPMMA blend sample containing different PMMA regrind content. The observation into the polymer morphology was performed using the Scanning Electron Microscopy (SEM) on the cross-section specimen on the break side while testing the tensile strength in order to determine the results of the interaction between ABS and PMMA. Fig. 3 presents the measurement result with a magnification of $200 \mathrm{X}$.

From Fig. 3, it can be seen easily that the blend of ABS resins with PMMA at a percentage of $10 \%$ did not result in fibril formation, and when the PMMA content was increased to $30 \%$, cavities existed which were assumed to be resulting from fibril formation. This brittle area expanded since the beginning of the fracture formation. This data confirmed that the blend containing 10\% PMMA still has the properties such as high impact materials and suitability for engineering polymers.

\section{Determination of the Thermal Properties of the Blended Product}

The Differential Scanning Calorimeter curves 
a) $\mathrm{ABS}:$ PMMA regrinds $(90: 10)$

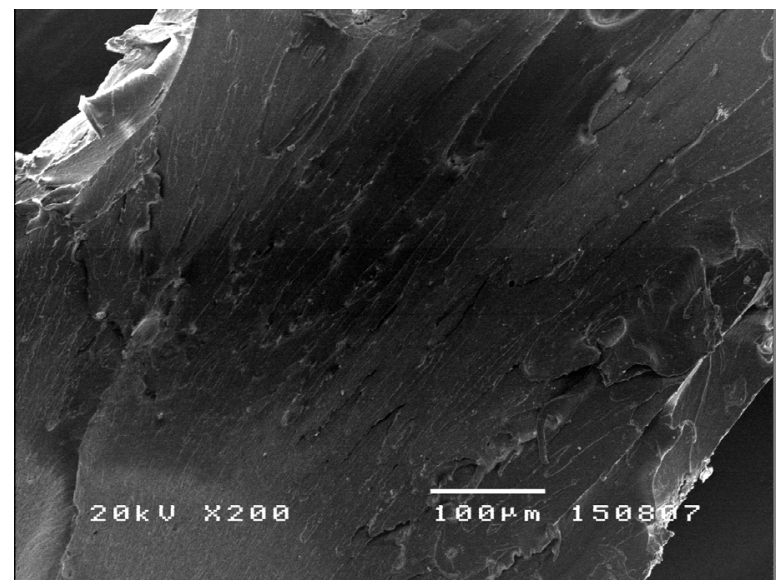

b) ABS:PMMA regrinds (70:30)

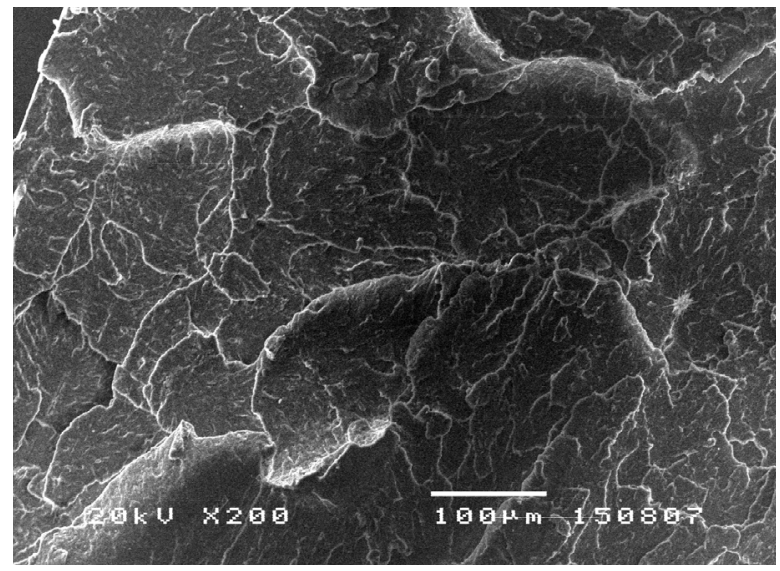

Fig. 3. SEM images of the PMMA-ABS blend containing a) $10 \%$ and b) 30\% PMMA regrind.

of the pure ABS and the ABS-PMMA blend containing 10\% PMMA are shown in Fig. 4.

From Fig. 4(a), it can be seen that the DSC profile for pure $\mathrm{ABS}$ had a single glass transition temperature $(\mathrm{Tg})$ of approximately $178.02^{\circ} \mathrm{C}$ and
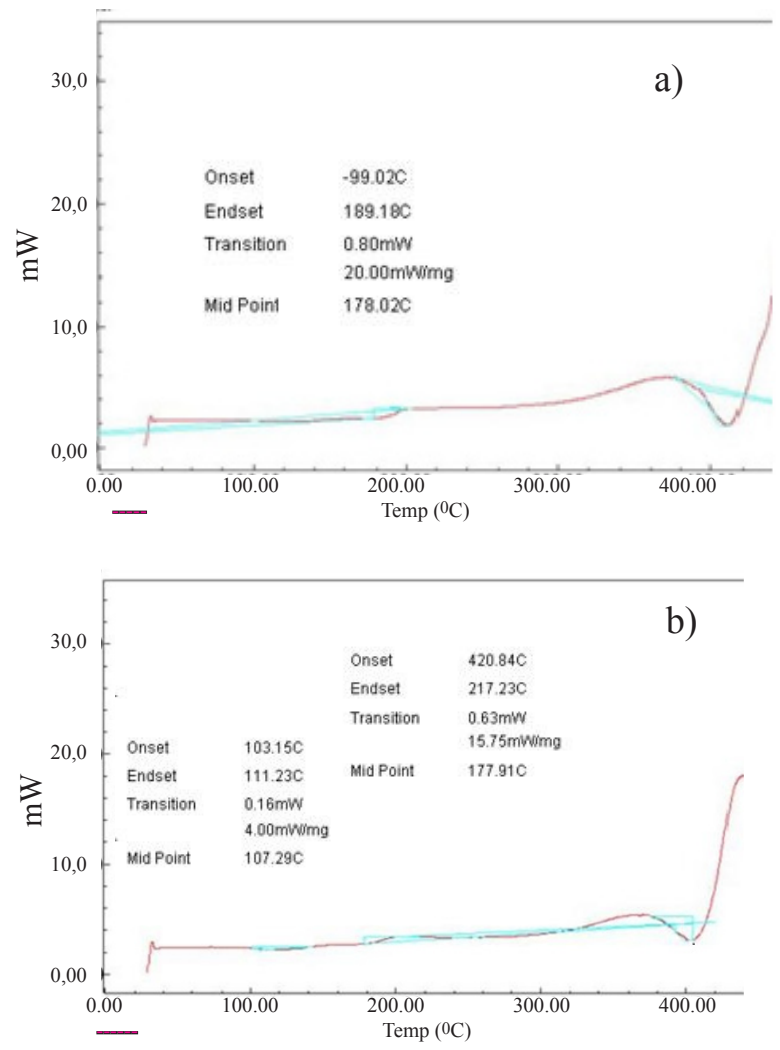

Fig. 4. The DCS of a) ABS: PMMA (100: 0) and b)ABS: PMMA (90:10).

its melting point (Tm-blend) was $410.36^{\circ} \mathrm{C}$, while in Fig. 4(b) the ratio of ABS to PMMA regrind by 90:10 of the sample had two Tg values, namely $107.29{ }^{\circ} \mathrm{C}$ and $177.91{ }^{\circ} \mathrm{C}$, and a single melting point by $404{ }^{\circ} \mathrm{C}$. Two glass transition temperatures in the DSC profile were predicted as the $\mathrm{Tg}$ of PMMA and ABS respectively. The differential between the $\mathrm{Tg}$ values $(\Delta \mathrm{Tg})$ was calculated by subtracting the value of Tg-ABS from that of Tg-PMMA. The values of the resulting Tg-ABS, Tg-PMMA regrind, $\Delta \mathrm{Tg}$, and melting point of the

Table 2. The Tm-blend and the $\Delta \mathrm{Tg}$ based on the PMMA content.

\begin{tabular}{ccccc}
\hline ABS:PMMA ratio $(w / w)$ & Tg-ABS & Tg-PMMA & $\Delta$ Tg & Tm-blend \\
\hline $100: 0$ & - & 178.02 & & 410.36 \\
$90: 10$ & 107.29 & 177.91 & 70.62 & 404.00 \\
$80: 20$ & 111.54 & 171.69 & 60.15 & 390.13 \\
$70: 30$ & 107.34 & 173.41 & 66.07 & 390.43 \\
$60: 40$ & 105.33 & 175.55 & 70.22 & 389.51 \\
\hline
\end{tabular}

Note:

$\Delta \mathrm{Tg} \quad:$ Differential between Tg PMMA and Tg ABS at certain ratios

Tm-blend : Melting point 
blend are presented in Table 2 .

Table 2 shows that the presence of a $\Delta \mathrm{Tg}$ value which as not equal to zero indicated that $\mathrm{ABS}$ and PMMA are not fully miscible with each other, and to generate a $\Delta \mathrm{Tg}$ value which is equal to zero, the blend needs a compatibilizer (Zhou et al., 2014). On the other hand, each blend had a single melting point ranging from 390 to $410^{\circ} \mathrm{C}$, suggesting that the sample was fully melted during the preparation process. An increased PMMA amount resulted in a decreased melting temperature of the blend.

\section{CONCLUSIONS}

PMMA products which are rejected can be reused as substitute materials for ABS resins in the production of high-abuse applications, such as lamp holders. The NMR analysis showed that the resins contained $21.6 \%$ butadiene monomer, which was greater than the required value for materials with high-impact class application. The blend of resins and rejected PMMA $(10-30 \% \mathrm{w} / \mathrm{w})$ could increase the tensile strength value and decrease Izod impact strength and elongation percentage. The morphological analysis showed that this increased PMMA content may also result in widespread brittle areas. Since the blend was designed without compatibilizers, the DSC analysis indicated that the resulting blend in any ratios was not completely miscible. It is revealed that $\mathrm{ABS}$ resins containing 10\% PMMA was the best blend for the polymer engineering application and this blend still had adequate properties and the elastomer content required.

\section{ACKNOWLEDGEMENTS}

The authors would like to thank Dr. B. Sugiono from the Faculty of Mathematics and Natural Science of the University of Indonesia and Dr. A. Haryono from the Research Center for Chemistry of the Indonesian Institute of Sciences for their valuable assistance.

\section{REFERENCES}

Al-hydary, I., Manocha, L., \& George, P. (2012). Preparation and characterization of PMMA-ABS Blend. The Iraqi Journal of mechanical and material engineering, 12 (4), 709-722.

Alper, N., Sen, S., Atilla, M., \& Nugay, N. (2006). Clay PMMA Nanocomposite by Photoinitiated Radical Polymerization Using Intercalated Phenacyl Pyridium Salt Initiators. Macromolecular Chem- istry and Physics, 207, 820-836, http://dx.doi.org/10.1002/macp.200500511

BSN (Badan Standardisasi Nasional). (2009). Standard Nasional Indonesia SNI 7398: 2008: Pemantul cahaya (retro-reflektor) kendaraan bermotor, kereta gandengan dan kereta tempelan, Indonesia: BSN.

Buthainadan, I., \& Kadum, K. (2010). Influence of Polymer Blending on Mechanical and Thermal Properties. Modern Applied Science Canadian Center of Science and Education, 4 (9).

Gaur, M., Shukla, P., Tiwari, R., \& P., S. S. (2008). New Approach for the Measurement of Glass Transition Temperature of Polymer. Indian Journal of Pure and Applied Physics, 46, 535-539.

Kenplas.(2006). Trouble Shooting for Injection Molding Process. http://www.kenplas.com/service/ imtroubleshooting.aspx Retrieved: 23rd May 2016

Kuo, C. C., Liu, L. C., Teng, W. F., Chang, H. Y., Chien, F. M., Liao, S. J., Chen, C. M. (2016). Preparation of starch/acrylonitrile-butadiene-styrene copolymers (ABS) biomass alloys and their feasible evaluation for 3D printing applications. Composites Part B: Engineering, 86, 36-39, http://dx.doi. org/10.1016/j.compositesb.2015.10.005

Li, W., Schlarbdan, A., \& Evstatiev, M. (2009). Effect of Viscosity Ratio on the Morphology of PET Microfibrils in Uncompatibilized and Compatibilized Drawn PET/PP/TiO2 Blends. Journal of Polymer Science: Part B: Polymer Physics, 47, 555-562, http://dx.doi.org/ 10.1002/polb.21658

Oepen, S., \& Gottschalk, A. (2011). Styrene copolymers (ABS, ASA, SAN, MABS, and ABS blends). Kunststoffe International, 101(10), 22-26.

Polli, H., Pontes, L. A. M., Araujo, A. S., Barros, J. M. F., \& Fernandes, V. J. (2009), Degradation behavior and kinetic study of ABS polymer. Journal of Thermal Analysis and Calorimetry, 95(1),131134 , http://dx.doi.org/10.1007/s10973-006-7781-1

Sankar, V., Kumar, T., \& Rao, K. (2004). Preparation, characterisation and fabrication of intraocular lens from photo-initiated polymerized poly (methyl methacrylate). Trends Biomater. Artif. Organs. , 17(2), 24-30.

Tsui, C.-C., Wei, H.-C., Chang, W.-F., \& Su, G.-D. J. (2012). Design and fabrication of a mid-wavelength infrared Fresnel lens via liquid poly(methyl methacrylate). Journal of Micromechanics and Microengineering, 22(4), 045010.

Zhou.J.C., Wang, S.H., Lin, S.X, Huang, J., and Xu, 
L.L. (2014). Effect of compatibilizer on the strength of ABS/PMMA blends. Materials Science and Engineering, 62, 012030 